\title{
Structural and functional evidence that a B chromosome in the characid fish Astyanax scabripinnis is an isochromosome
}

\author{
CARLOS A. MESTRINER $\dagger$, PEDRO M. GALETTI JR†*, SANDRO R. VALENTINI§, \\ ITAMAR R. G. RUIZ†, LUCIANO D. S. ABEL†, ORLANDO MOREIRA-FILHO† \\ \& JUAN P. M. CAMACHO \\ $\dagger$ Departamento de Genética e Evolução, Universidade Federal de São Carlos, via Washington Luiz, \\ Km 235 Caixa Postal 676, 13565-905 São Carlos, SP, Brazil; ¥Departamento de Ciências Biológicas, \\ Faculdade de Ciências Farmacêuticas - UNESP, 14801-902 Araraquara, SP, Brazil; § Genética, \\ Instituto Butantã, Av. Vital Brasil 1500, 05503-900 São Paulo, SP, Brazil; - Departamento de Genética, \\ Universidad de Granada, 18071 Granada, Spain
}

\begin{abstract}
Astyanax scabripinnis possesses a widespread polymorphism for metacentric B chromosomes as large as the largest chromosome pair in the A complement. On the basis of C-banding pattern, it was hypothesized that these $\mathrm{B}$ chromosomes are isochromosomes that have arisen by means of centromere misdivision and chromatid nondisjunction. In the present paper we test this hypothesis by analysing (i) the localization of a repetitive DNA sequence on both B chromosome arms, and (ii) synaptonemal complex formation, in order to test the functional homology of both arms. Genomic DNA digested with $K p n I$ and analysed by gel electrophoresis showed fragments in a ladder-like pattern typical of tandemly repetitive DNA. These fragments were cloned and their tandem organization in the genome was confirmed. A 51-bp long consensus sequence, which was AT-rich (59\%) and contained a variable region and two imperfect reverse sequences, was obtained. Fluorescence in situ hybridization (FISH) localized this repetitive DNA into noncentromeric constitutive heterochromatin which encompasses the terminal region of some acrocentric chromosomes, the NOR region, and interstitial polymorphic heterochromatin in chromosome 24. Most remarkably, tandem repeats were almost symmetrically placed in the two arms of the B chromosome, with the exception of two additional small clusters proximally located on the slightly longer arm. Synaptonemal complex (SC) analysis showed 26 completely paired SCs in males with 1B. The ring configuration of the B univalent persisting until metaphase I suggests that the two arms formed chiasmata. All these data provided strong support for the hypothesis that the $\mathrm{B}$ chromosome is an isochromosome.
\end{abstract}

Keywords: Astyanax scabripinnis, B chromosomes, FISH, heterochromatin, isochromosome, satellite DNA.

\section{Introduction}

B chromosomes, also referred to as supernumerary or accessory chromosomes, are 'additional dispensable chromosomes that are present in some individuals from some populations in some species, which have probably arisen from the A chromosomes but that follow their own evolutionary pathway' (Camacho \& Parker, 1993). The molecular analysis of $\mathrm{B}$ chromosomes has revealed that they are mostly composed of satellite DNA, which is consistent with their heterochromatic nature. Some of these satellite DNAs are specific to Bs whereas others are

*Correspondence. E-mail: galettip@power.ufscar.br

(C) 2000 The Genetical Society of Great Britain. shared with the A chromosomes (reviewed in Beukeboom, 1994; Hackstein et al., 1996; Camacho et al., in press). In some cases, satellite DNA has provided a useful tool to ascertain the intraspecific (López-León et al., 1994) or interspecific (Mcallister \& Werren, 1997) origin of B chromosomes (see also Camacho et al., 2000).

A metacentric macrochromosome $\mathrm{B}$, with different amounts of C-heterochromatin, has been described in some populations of the characid fish Astyanax scabripinnis (for review, see Vicente et al., 1996). On the basis of the roughly symmetrical pattern of C-banding response of the two arms of this B, Vicente et al. (1996) suggested that this B is an isochromosome that arose by misdivision and nondisjunction of the centromere. This 
kind of B chromosome is relatively frequent in orthopteran insects, where chiasma formation between the two arms has been shown to lead to the formation of ring B univalents during the meiotic metaphase I (for review, see Hewitt, 1979).

The available evidence on the existence of B isochromosomes is mainly based on C-banding pattern and the formation of ring $\mathrm{B}$ univalents. In the present paper, we analyse the isochromosome nature of a metacentric $\mathrm{B}$ in the fish A. scabripinnis by means of: (i) the molecular analysis of a satellite DNA, including its isolation, cloning and sequencing; (ii) FISH analysis of its chromosome localization; (iii) synaptonemal complex formation; and (iv) meiotic configuration of the $\mathrm{B}$ chromosome at meiotic metaphase I. These approaches have permitted us to test the hypothesis of Vicente et al. (1996) that this B chromosome is an isochromosome, in terms of both structural (approaches i and ii) and functional (approaches iii and iv) homology between the two B arms.

\section{Materials and methods}

\section{Animals, chromosome preparation, and $C$ banding}

Astyanax scabripinnis specimens were collected from the 'Córrego das Pedras' stream (Campos do Jordão-SP, Brazil), at $1720 \mathrm{~m}$ altitude; 29 animals (15 males and 14 females) were characterized cytogenetically. Chromosome preparations followed the procedure described by Bertollo et al. (1978) and C-banding was performed according to Sumner (1972). Ten animals (five males and five females) were chosen for further molecular analysis. Conventional meiosis and synaptonemal complex were visualized by means of the techniques described in Bertollo \& Mestriner (1998).

\section{DNA cloning and sequencing}

Genomic DNA was extracted from kidney as previously described (Cortadas \& Ruiz, 1988). Repetitive DNA fragments produced by digesting genomic DNA with $K p n I$ were eluted from the agarose gel and cloned into pGEM4 vector (Promega). Ligation products were used to transform E. coli HB101. Nucleotide sequences of selected clones were determined according to the dideoxy chain termination method (Sanger et al., 1977), using $\left[\alpha-{ }^{35} \mathrm{~S}\right] \mathrm{dCTP} 3000 \mathrm{Ci} / \mathrm{mmol}$ and the T7 DNA sequencing kit (Pharmacia).

\section{Southern blot analysis}

Genomic DNA was digested and fractionated in agarose gels. After depurination, denaturation and neutraliza- tion, DNA was transferred to nylon membrane (Southern, 1975). The DNA probe was prepared by random primer extention (Feinberg \& Vogelstein, 1984), using $\left[\alpha-{ }^{32} \mathrm{P}\right] \mathrm{dCTP} 3000 \mathrm{Ci} / \mathrm{mmol}$ and an oligolabelling system (GibcoBRL). DNA was hybridized at $42^{\circ} \mathrm{C}$ overnight $(50 \%$ formamide; $5 \times$ SSC; $50 \mathrm{~mm}$ sodium phosphate buffer $\mathrm{pH} 6.8 ; 0.1 \%$ SDS; and $5 \times$ Denhart's solution). Filters were extensively washed (twice in $2 \times$ SSPE; $0.1 \%$ SDS for $15 \mathrm{~min}$ at room temperature, and twice in $0.1 \times \mathrm{SSPE}, 0.1 \% \mathrm{SDS}$ for $30 \mathrm{~min}$ at $60^{\circ} \mathrm{C}$ ) and exposed to X-ray film.

\section{Fluorescence in situ hybridization - FISH}

In situ hybridization was carried out with biotinylated probe, prepared with a nick translation kit (Boehringer). Chromosomal DNA was denatured in $70 \%$ formamide; $2 \times \mathrm{SSC}$ for $5 \mathrm{~min}$, at $70^{\circ} \mathrm{C}$. DNA was hybridized at $37^{\circ} \mathrm{C}$ overnight in a moist chamber $(1 \mu \mathrm{g}$ of denatured probe; $50 \%$ formamide; $10 \mathrm{mg} \mathrm{mL}^{-1}$ dextran sulphate; $2 \times \mathrm{SSC} ; 5 \mathrm{mg} \mathrm{mL}^{-1}$ salmon sperm DNA). Hybridized probe was detected with avidin-FITC labelled (SIGMA) after one round of amplification with antiavidin biotin conjugate (SIGMA). Slides were counterstained with propidium iodide $\left(0.5 \mu \mathrm{g} \mathrm{mL}^{-1}\right.$ in $22.5 \%$ glycerol $)$.

\section{Results}

\section{Sample composition}

Previous analysis of the A. scabripinnis population from Córrego das Pedras had shown female-biased sex-ratio distortion associated with the presence of the B chromosome, which was much more frequent in females than in males (Vicente et al., 1996). The present sample was consistent in showing $13.3 \%$ of males with $1 \mathrm{~B}$ and $92.8 \%$ of females with $1 \mathrm{~B}$ or $2 \mathrm{~B}$. C-banding showed the presence of faint paracentromeric $\mathrm{C}$-bands on all chromosomes, conspicuous C-bands distally located on the long arm of several acrocentric A chromosomes, a C-band distally located on the short arm of chromosome 10, which coincides with the location of a NOR, and interstitial C-bands on the two arms of the B chromosome (Fig. 1). This C-banding pattern does not differ from that previously reported for this population (Vicente et al., 1996).

\section{Cloning and characterization of satellite DNA}

Genomic DNA from A. scabripinnis was digested with different restriction enzymes, and $K p n I$ yielded repetitive DNA bands in a ladder-like pattern (multimeric fragments of $51 \mathrm{bp}$ ) after electrophoresis. Fragments corresponding to the $51 \mathrm{bp}$-multimers were eluted from the

(C) The Genetical Society of Great Britain, Heredity, 85, 1-9. 
Fig. 1 C-banding pattern of Astyanax scabripinnis. M, metacentric; SM, submetacentric; ST, subtelocentric and A, acrocentric chromosomes. Bar: $5 \mu \mathrm{m}$.

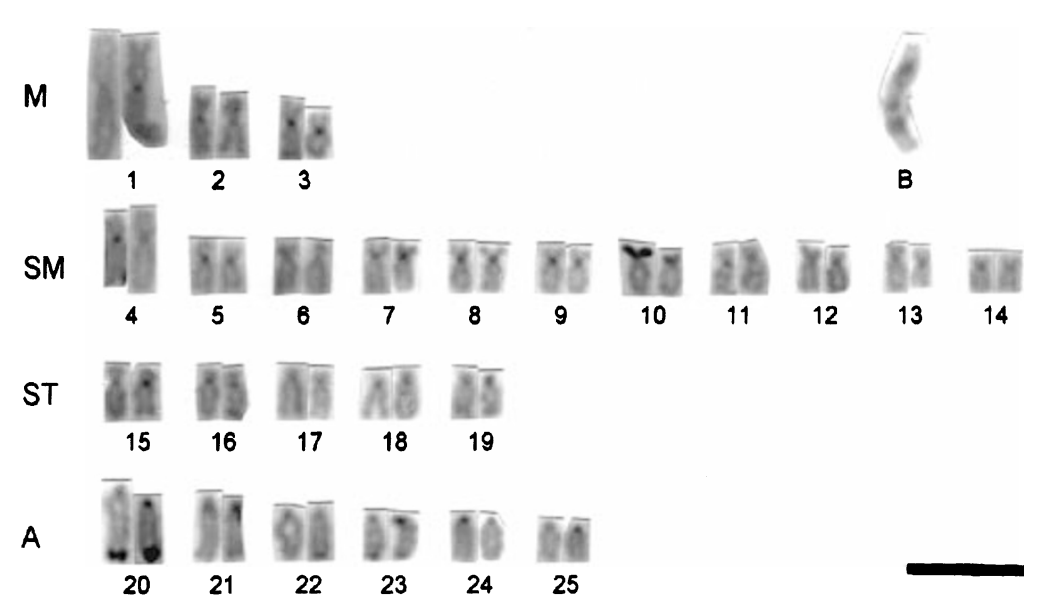

gel, pooled, and cloned into pGEM4 vector. Fifteen recombinant clones (pAs51-I up to pAs51-XV), representing a repetitive DNA family, hereafter named As51, were recovered.

Genomic DNA digested with $K p n I$ from all animals was hybridized to one of the selected plasmids (pAs51II) in order to determine the organization of this repetitive DNA family and compare band patterns among fish with and without B chromosomes. This Southern analysis revealed fragments in a ladder-like pattern, as described above, confirming their tandem organization. Such organization was present in nine of the 10 specimens analysed. The remaining one was a $0 \mathrm{~B}$ female. Additionally, fragments of high molecular size were also detected in all animals, but no relationship could be established between the bands and B chromosome presence (Fig. 2).

Among the 15 recovered clones, two were related to dimeric bands, 10 to trimeric bands, and three to tetrameric bands (data not shown); two trimers and one tetramer were considered for sequencing. Both trimers, pAs51-II and VI, and the tetramer, pAs51-XV, exhibited lengths of $153 \mathrm{bp}, 154 \mathrm{bp}$, and $204 \mathrm{bp}$, respectively (Fig. 3). The monomeric units (M1-M4) were 51-bp long, but M1 from pAs51-VI showed an insertion at position 27. All 10 units were aligned and the consensus sequence, which is 59\% AT-rich, was determined. By such analysis the As51 repetitive DNA family could be characterized by seven-point mutations (positions 1, 2, $4,5,12,13$ and 14) which recognized two kinds of monomers: As51-A (represented by the M1 monomer from all three clones) and As51-B (remaining monomers). Thus, monomers As51-A and As51-B are interspersed to each other and, perhaps, could represent two subfamilies in this satellite DNA. One such mutation (position 1) is responsible for the loss of the KpnI restriction site. Mutations are less frequent between positions 29 and 52, where only four substitutions were

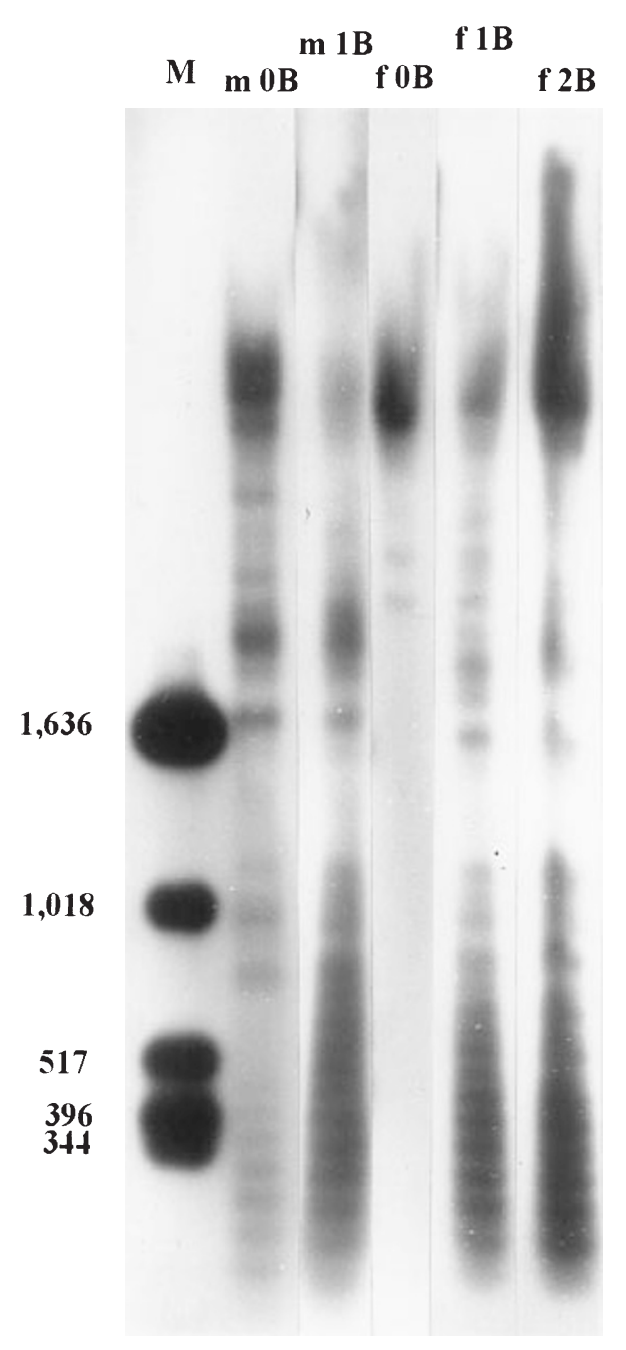

Fig. 2 Genomic DNA from five Astyanax scabripinnis, with different constitution for the B chromosome, completely digested with KpnI and probed with pAs51-II. M, Molecular weight markers expressed in bp; $\mathrm{m}$, male; f, female. 


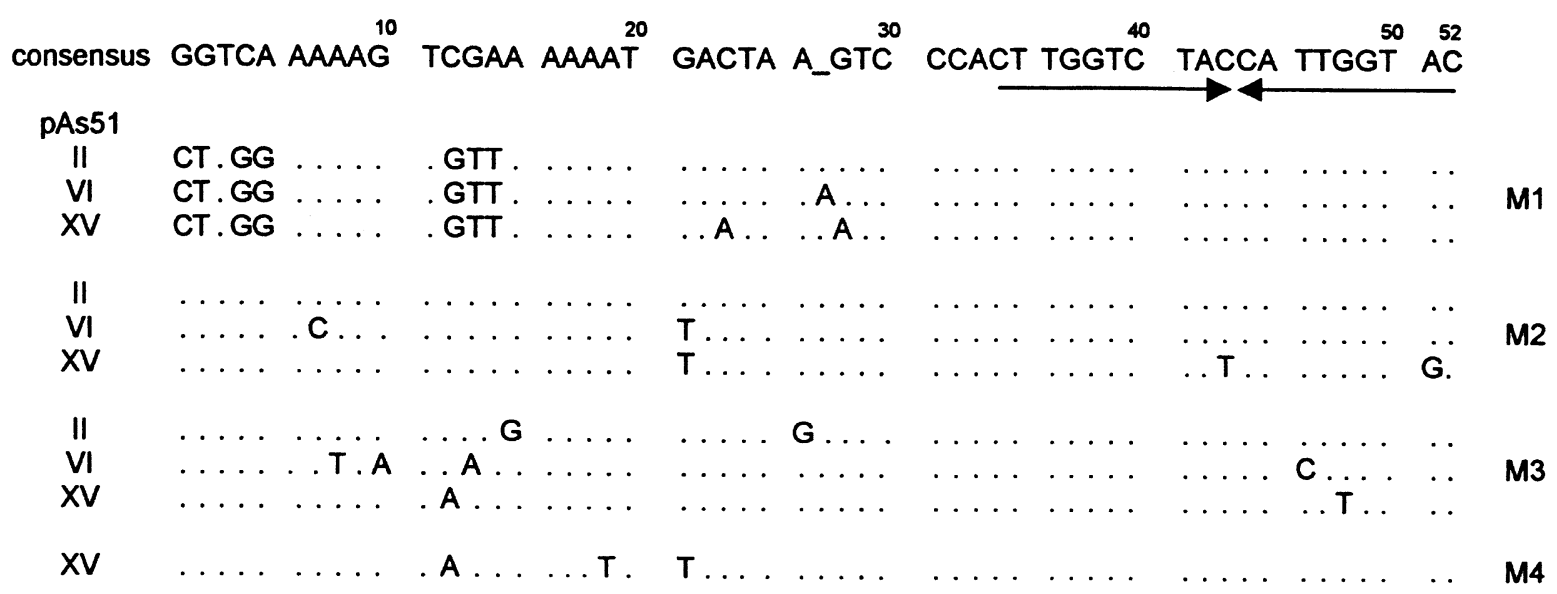

Fig. 3 Aligned sequences from the clones pAs51-II, VI and XV and compared to the consensus sequence (on the top). M1, M2, M3 and M4 are the monomers 1, 2, 3 and 4 from each clone. Dots represent the same nucleotide as that in the consensus sequence. Arrows indicate the imperfect reverse sequences.

found among all monomers. Two imperfect reverse sequences are present within this region (Fig. 3). The consensus sequence appears in GenBank under the accession number U87962.

Southern blot hybridization of the A. scabripinnis satellite DNA on several fish species DNA did not show any detectable cross-hybridization, except for an Astyanax species (A. fasciatus) among three studied thus far (data not shown).

A search in the GenBank/EMBL Data Bank showed $58.8 \%$ DNA sequence similarity with a portion of the Anopheles gambiae RT2 retroposon. Furthermore, this sequence was translated into all six reading frames (both strands) and a slight similarity was found with the transposase gene of the TN4430 transposon of Bacillus thuringiensis.

\section{Localization of satellite DNA}

Fluorescence in situ hybridization revealed that the As51 repetitive DNA family was localized in a small portion of the genome of Astyanax scabripinnis (Fig. 4). Its distribution was noncentromeric, entailing all distal C-bands on A chromosomes and the interstitial C-bands on the B chromosome (compare Figs 1 and 4). It is thus contained in the distal region of the long arm of some acrocentric A chromosomes, the short arm of chromosome 10 (NOR region), and interstitially along the two arms of the B chromosome. Furthermore, interindividual variation in the number of acrocentric chromosomes bearing As51 clusters was observed (0-4). The hybridization pattern provided by the different chromosomes carrying As51 clusters could be clearly distinguished in interphase cells. Observe in Fig. 4(b) the close correspondence between metaphase and inter- phase for the number and size of hybridization signals in the acrocentrics, that are clearly distinguishable from those in the NOR region and the $\mathrm{B}$ chromosome. Another example is shown in Fig. 4(d), where the two

Fig. 4 Karyotypic distribution of the As51 repetitive DNA family in Astyanax scabripinnis, revealed by fluorescence in situ hybridization. (a) Mitotic metaphase cell from an individual carrying $1 \mathrm{~B}$ and one distal supernumerary segment on an acrocentric chromosome (AC). FISH signals are observed interstitially on the $\mathrm{B}$ chromosome, distally on the AC chromosome and, slightly duller, on the NOR of chromosome 10 (arrow). (b) Metaphase and interphase cells from an individual with $1 \mathrm{~B}$ and four distal supernumerary segments, two being larger (AC) than the other two (ac). In addition to the observations in (a), notice the presence of the different FISH signals in the interphase cell (on the right) whose characteristic size and appearance permits the interphase localization of each of the chromosomes bearing the As51 probe. (c) Mitotic metaphase from a $2 \mathrm{~B}$ individual carrying one supernumerary segment (AC). (d) Interphase cells from the same individual as in (b) to show that the different FISH signals permit the identification of the As51-bearing chromosomes. Notice that the B chromosome seems to be composed of two chromatids, which suggests that the interphase could be in $\mathrm{G}_{2}$. (e) Selected B chromosomes from different cells and/or individuals showing the almost symmetrical pattern of distribution of the As51 probe among the two arms. Notice in the B on the right, which presumably is bent by the centromere, that the two B arms are slightly unequal. Note in the remaining Bs that the larger arm possesses two proximal signals that are absent from the short arm, and this is the cause for the inequality of the two arms. On the extreme right, panel (e) shows that the interstitial C-band on chromosome 24, reported by Vicente et al. (1996), contains the As51 repetitive DNA. $\operatorname{Bar}=5 \mu \mathrm{m}$.

(C) The Genetical Society of Great Britain, Heredity, 85, 1-9. 
chromatids of the B can be distinguished in the lower nucleus.

The 0B female shown in Fig. 2, that lacked the ladderlike pattern in the Southern blot, showed only two hybridization signals on the chromosome 10 NORs, and it was the only one specimen in the analysed sample, that lacked heterochromatin on the acrocentric chromosomes (result not shown). This suggests that whereas the heterochromatin located on the acrocentric A chromosomes and the B chromosome is composed of tandemly arrayed As51 repeats, that in the NOR might have a different organization. In addition, the less intense hybridization signal on the NORs at chromosome 10, compared to those on the acrocentric chromosomes or the B, suggests a lower density of As51 repeats in the NOR.

An animal carrying an interstitial heterochromatin block in chromosome 24 was investigated separately, because this chromosome, by being the only A chromosome carrying interstitial C-heterochromatin, was proposed as the possible ancestor of the B (Vicente et al., 1996). This C-block seems to be polymorphic in this
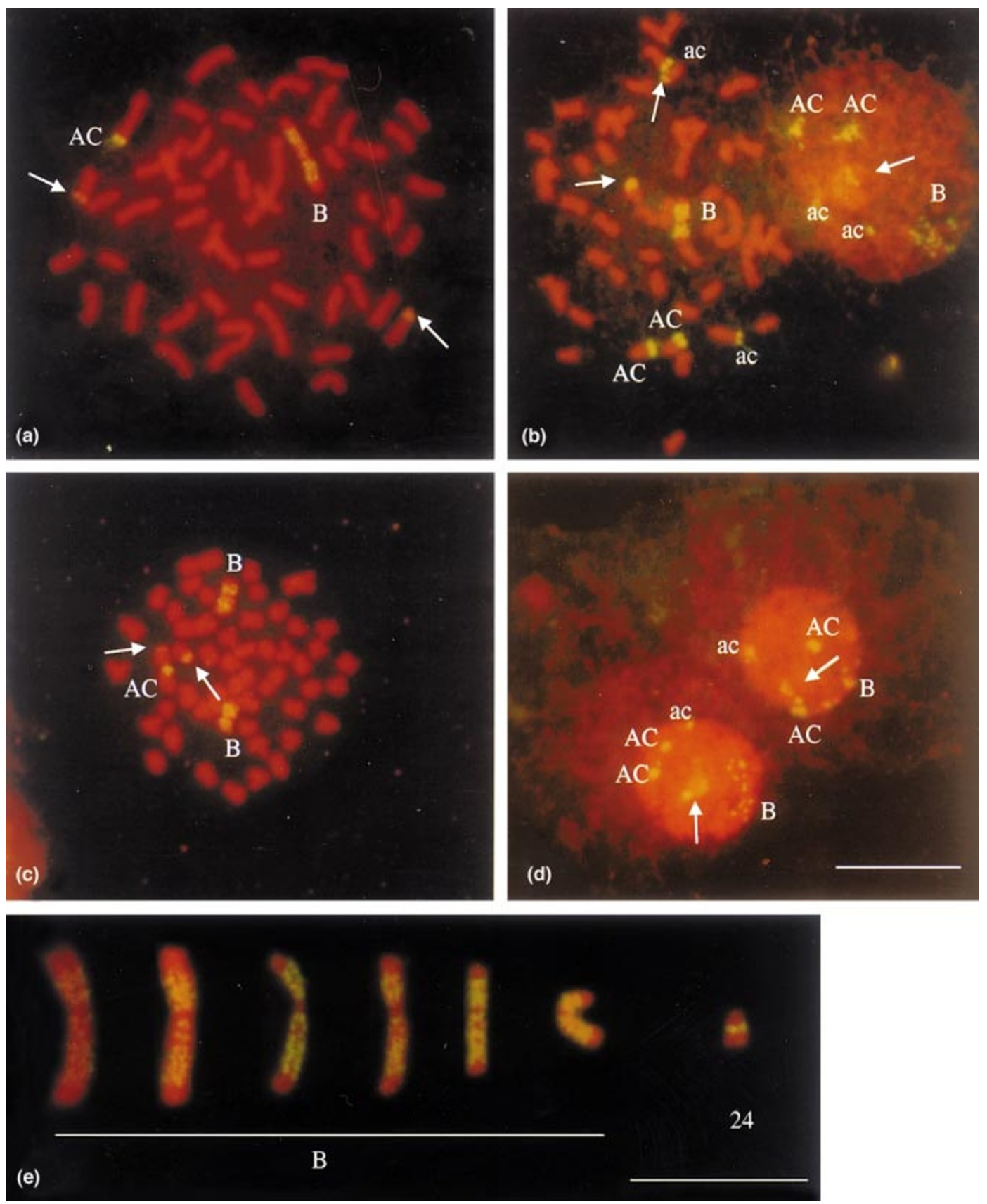

(C) The Genetical Society of Great Britain, Heredity, 85, 1-9. 
population as it was not detected in the present sample, but we could use material from previous samples. The FISH analysis showed that this interstitial C-band was also composed of As51 repetitive DNA (Fig. 4e).

Although the B chromosome is referred to as metacentric (on the basis of Levan's criterion), it shows one arm slightly larger than the other. Figure 4(e) shows a collection of Bs from different cells showing arm inequality (in particular the one on the right) and the presence of two additional small clusters of the As51 repetitive DNA in the long arm.

\section{Synaptonemal complex analysis}

Figure 5 shows surface-spread prophase I cells from 1B males of $A$. scabripinnis. The presence of a high degree of asynapsis in most autosomes as well as homologous presynaptic alignment in some of them, indicated that Fig. 5(a) is a zygotene cell where synapsis is incomplete. However, there was a completely formed SC in the periphery of the cell, which was not observed in zygotene cells from $0 \mathrm{~B}$ males, suggesting that this $\mathrm{SC}$ corresponded to the $\mathrm{B}$ chromosome. This indicated that the B chromosome pairs earlier in zygotene than the A set does. By pachytene, 26 completely paired SCs were observed in 1B males, 25 of which correspond to the A bivalents and the remaining (but unidentifiable) one should correspond to the autopaired B univalent.

\section{Analysis of male and female meiosis}

The conventional analysis of meiosis in both sexes is shown in Fig. 6. In 1B females, the B univalent showed a diplotene-like appearance in cells where the A bivalents were at pachytene, even showing an interstitial chiasma (Fig. 6a,b). This could be another sign of the precocious meiotic behaviour of the $\mathrm{B}$ univalent compared to that of A bivalents. The heteropycnosis of the B univalent makes it clearly distinguishable from the A bivalents. In $1 \mathrm{~B}$ males, the B chromosome was always observed as a ring-univalent (Fig. 6c-e), which suggests the formation of a distal chiasma between the two B arms.

\section{Discussion}

Our results provide strong support for the hypothesis that the large metacentric B chromosome in the fish A. scabripinnis is an isochromosome, because its two arms have displayed both structural and functional homology. The structural evidence came from the largely symmetrical presence of the As51 repetitive DNA in both B arms. The functional evidence came from the meiotic behaviour of the $\mathrm{B}$ in both sexes. The two arms of the B-univalent were the first to complete



Fig. 5 Synaptonemal complex (SC) visualization in Astyanax scabripinnis by means of surface spreading. (a) Zygotene cell from a $1 \mathrm{~B}$ individual showing the presence of a high degree of asynapsis in most autosomes as well as homologous presynaptic alignment in some of them (arrow). The only completely formed SC was localized at the periphery of the cell and was not observed in equivalent cells from $0 \mathrm{~B}$ individuals, which indicates that it is the B chromosome. (b) Pachytene cell from a $1 \mathrm{~B}$ individual showing 26 completely formed SCs, 25 of which should correspond to the A bivalents and the remaining one (but unidentifiable) should be the autopaired B univalent. $\operatorname{Bar}=5 \mu \mathrm{m}$.

synaptonemal complex formation, suggesting that their physical proximity conferred an advantage in the search for homology. A similar observation has been reported

(C) The Genetical Society of Great Britain, Heredity, 85, 1-9. 


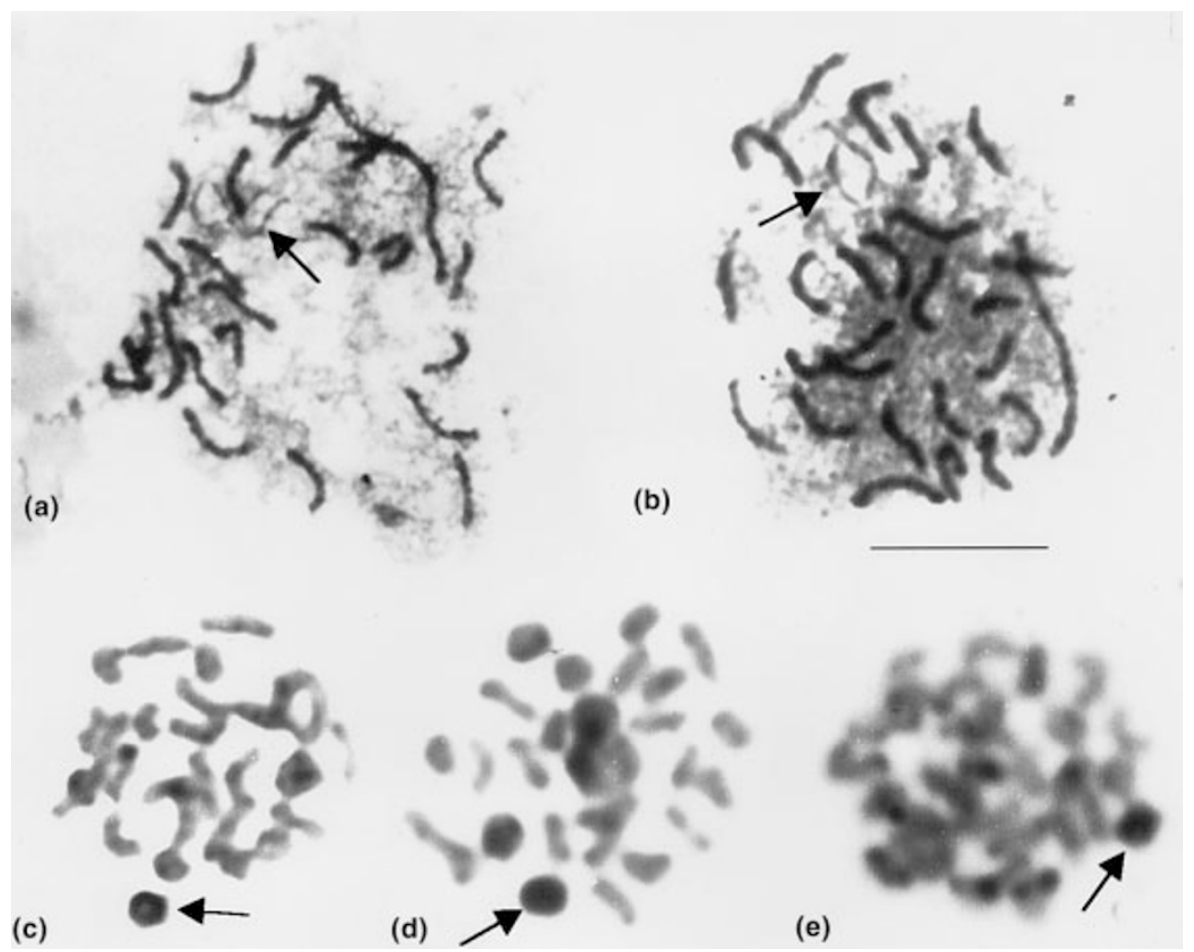

Fig. 6 Meiosis in both sexes of Astyanax scabripinnis. (a,b) Pachytene cells from 1B females showing a negatively heteropycnotic autopaired B chromosome (arrow), with an interstitial chiasma between its two arms. (c,e) C-banded metaphase I cells from 1B males showing the B positively C-banded and forming a ring univalent (arrow). Bar $=5 \mu \mathrm{m}$.

for the iso-Bs in the grasshoppers Euthystira brachyptera and Myrmeleotettix maculatus (Fletcher \& Hewitt, 1988). In plants, however, the iso-Bs hitherto analysed by surface-spreading show a period of pairing which is delayed relative to the A-set (Jones et al., 1989; Santos et al., 1995). This seems to suggest important differences in the relationship between physical proximity and homology search between plants and animals, that should merit future research. The precocity of iso-B pairing determined a diplotene-like behaviour in pachytene cells during female meiosis. The functional homology of both B arms was clearly apparent from chiasma formation in the B univalents and their persistence until metaphase I giving rise to ring $\mathrm{B}$ configurations.

To our knowledge, we are providing here the most complete evidence yet for the isochromosome nature of a B chromosome. Until now, it had been deduced from B chromosomes' ability to form ring univalents in metaphase I (for review, see Hewitt, 1979) and/or the existence of a symmetrical pattern of C-banding (Henriques-Gil et al., 1984; López-León et al., 1993). In one case, the plant Crepis capillaris, the symmetrical presence of ribosomal DNA in both B arms has been shown (Maluszynska \& Schweizer, 1989). In A. scabripinnis, the two B arms share a specific DNA and behave as completely homologous chromosome arms. The mech- anism generating iso-B-chromosomes is centromere misdivision and nondisjunction, each chromatid becoming an arm of the metacentric B. Consequently, the two arms should show complete homology, unless other subsequent rearrangements have modified the original pattern. In A. scabripinnis, the slight arm inequality is explained by a small pericentric inversion moving the most proximal cluster of the As51 repetitive DNA from the short to the long arm. This inversion should have happened after the origin of a perfectly symmetrical iso-B.

Most B chromosomes whose DNA composition has hitherto been analysed have shown that they mainly contain repetitive DNA (for review, see Beukeboom, 1994). As far as we know, the present paper is the first one to show the genetic composition of any part of the repetitive DNA from a fish $\mathrm{B}$ chromosome. Most repetitive DNAs that have been located chromosomally by in situ hybridization have shown centromere localization (Haaf et al., 1993; Garrido-Ramos et al., 1995). In A. scabripinnis, however, the As51 repetitive DNA showed a noncentromeric localization, which seems to be rare in fish. It is almost restricted to supernumerary heterochromatin, specifically the iso-B and the polymorphic distal heterochromatic blocks on some acrocentric chromosomes. The only location on the standard 
A set was noted in the NORs of chromosome 10, where it seems to show a lower density of repeats, as is suggested by its less bright FISH signal. The interspersion of the As51 repeat into the rDNA spacers could explain such a lower density.

Nucleotide analysis of the As51 repeat has shown an AT-rich consensus sequence, which seems to be a common feature among fish repetitive DNAs hitherto reported (reviewed in Haaf et al., 1993; Garrido-Ramos et al., 1995).

The DNA sequence similarities, detected in the GenBank/EMBL Data Bank, with a portion of the Anopheles gambiae RT2 retroposon and, in a lesser extent, with the transposase gene of the TN4430 transposon of Bacillus thuringiensis, suggest that As51 sequences could have arisen from a movable element. A retrotransposable element (called NATE) is present in the B chromosome of the parasitoid wasp Nasonia vitripennis (McAllister 1995; McAllister \& Werren, 1997), and a retrotransposon appears to have been involved also with the transposition of chloroplast DNA into the repeat element $\mathrm{Bd} 49$ of the $\mathrm{B}$ chromosomes of Brachycome dichromosomatica (Franks et al., 1996).

Southern blot analysis has shown that As51 repetitive DNA must have at least two different organization patterns within the A. scabripinnis genome. Whereas the 51-bp long monomers are arranged tandemly in the supernumerary heterochromatin, the absence of a ladder-like pattern in a female lacking supernumerary heterochromatin (see Fig. 2) suggests that, at the NORs, they are interspersed with other sequences, presumably scattered into the spacers. Retroposons have been found inserted into the 28S RNA gene from some rDNA units in different insects. It has been shown that these retrotransposons probably move apart from rDNA in a sequence-specific manner and therefore suggested that rDNA units constitute a favourable niche for the invasion of selfish mobile elements (Xiong et al., 1988).

A final comment is merited on the origin of the A. scabripinnis B chromosome. Two groups of hypotheses explain B chromosome origin, one of them suggesting that they are derived from a member of the A set and the other that they are derived from a different species through interspecific hybridization (Green, 1990; Beukeboom, 1994). The existence of DNA sequences shared by the A and B chromosomes of a species supports the intraspecific hypothesis; however, the presence of DNA specific to the B chromosome that is present in the A set of a related species, gives support to the interspecific hypothesis. In A. scabripinnis, two hypotheses have been suggested to explain the origin of the large metacentric B chromosome, both based on chromosome size and morphology and restricted to intraspecific explanations. The first argues that this B chromosome originated from nondisjunction at meiosis of the first chromosome pair with subsequent heterochromatinization of the extra chromosome (Salvador \& Moreira-Filho, 1992). In an alternative hypothesis, it has been claimed that the metacentric B chromosome is an isochromosome, probably originated from chromosome 24 of the A complement, the only one showing an interstitial C band like the B (Vicente et al., 1996). As discussed above, the present data give clear support to the hypothesis that the $\mathrm{B}$ is an isochromosome. The specific A chromosome from which the B was derived, however, cannot be elucidated with the information available. It is true that the chromosome 24 that Vicente et al. (1996) found with an interstitial C-band is the only one found with such a localization, but this chromosome 24 variant is actually rare, and the very dynamic nature of this repetitive DNA, with its possible movable properties, makes such confirmation difficult. Microdissection of this $\mathrm{B}$ chromosome will allow additional molecular analysis. In addition, as B chromosomes with similar characteristics have been found in different A. scabripinnis populations (Maistro et al., 1994; Vicente et al., 1996) and also in other Astyanax species, it will very interesting to investigate whether they have a common origin and, even, whether they predate the origin of some of these species. For this purpose, the As51 repetitive DNA will undoubtedly constitute a powerful tool.

\section{Acknowledgements}

The authors thank Lucia E. Alvares, Roberto B. Flatschart and Lucia Regina Martelli for their help during the development of this research. The authors are also grateful to Departamento de Engenharia de Materiais (UFSCar) for allowing use of the electron microscope, to Fundação de Amparo à Pesquisa do Estado de São Paulo (FAPESP), and to Conselho de Desenvolvimento Científico e Tecnológico (CNPq) for financial support. J.P.M.C. is also grateful to the Spanish Dirección General de Enseñanza Superior (PB96-1433) and Plan Andaluz de Investigación (CVI-165).

\section{References}

Bertollo, L. A. C. AND Mestriner, C. A. 1998. The $\mathrm{X}_{1} \mathrm{X}_{2} \mathrm{Y}$ sex chromosome system in the fish Hoplias malabaricus. II. Meiotic analyses. Chromosome Res., 6, 141-147.

Bertollo, L. A. C., TAKAHASHI, C. S. AND MOREIRA-FILHO, O.. 1978. Cytotaxonomic considerations on Hoplias lacerdae (Pisces, Erythrinidae). Brazil. J. Genet., 1, 103-120.

BEUKeвоOM, L. W. 1994. Bewildering Bs: an impression of the 1st B-Chromosome Conference. Heredity, 73, 328-336.

(C) The Genetical Society of Great Britain, Heredity, 85, 1-9. 
CAMACHO, J. P. M. AND PARKer, J. 1993. First B Chromosome Conference. Miraflores de la Sierra, Madrid.

CAMACHO, J. P. M., SHARBEL, T. F. AND BEUKEBOOM, L. W. 2000. B chromosome evolution. Phil. Trans. R. Soc. B, 355, 163-178.

CORTADAS, J. AND RUIZ, I. R. G. 1988. The organization of ribosomal genes in diploid and tetraploid species of the genus Odontophrynus (Amphibia, Anura). Chromosoma, 96, 437-442.

FEINBERG, A. P., AND VOGELSTEIN, B. 1984. A technique for radiolabeling DNA restriction endonuclease fragments to high specific activity. Analyt. Biochem., 137, 266-267.

FLETCHER, H. L. AND HEWITT, G. M. 1988. Synaptonemal complex of univalent B chromosomes in the grasshoppers Euthystira brachyptera and Myrmeleotettix maculatus. Heredity, 60 , 383-386.

FRANKS, T. K., HOUBEN, A., LEACH, C. R. AND TIMMIS, J. N. 1996. The molecular organization of a $\mathrm{B}$ chromosome tandem repeat sequence from Brachycome dichromosomatica. Chromosoma, 105, 223-230.

GARRIDO-RAMOS, M. A., JAMILENA, M., LOZANO, R., RUIZ-REJÓN, C. AND RUIZ-REJÓN, M. 1995. The EcoRI centromeric satellite DNA of the Sparidae family (Pisces, Perciformes) contains a sequence motive common to other vertebrate centromeric satellite DNAs. Cytogenet. Cell Genet., 71, 345-351.

GREEN, D. M. 1990. Muller's Ratchet and the evolution of supernumerary chromosomes. Genome, 33, 818-824.

HAAF, T., SCHMID, M., STEINLEIN, C., GALETTI, P. M. JR AND WILLARD, H. F. 1993. Organization and molecular cytogenetics of satellite DNA family from Hoplias malabaricus (Pisces, Erythrinidae). Chromosome Res., 1, 77-86.

HACKSTEIN, J. H. P., HOCHSTENBACH, R., HAUSCHTECK-JUNGEN, E. AND BEUKeboom, L. w. 1996. Is the Y chromosome of Drosophila an evolved supernumerary chromosome? Bioessays, 18, 317-323.

HENRIQUES-GIL, N., SANTOS, J. L. AND ARANA, P. 1984. Evolution of a complex polymorphism in the grasshopper Eyprepocnemis plorans. Chromosoma, 89, 290-293.

HEWITT, G. M. 1979. Grasshoppers and crickets. In: John, B., (ed.) Animal Cytogenetics, Vol. 3: Insecta, 1: Orthoptera, 1-170. Gebrüder Borntraeger, Berlin.

JONES, G. H., WHITEHORN, J. A. F. AND ALBINI, S. M. 1989. Ultrastructure of meiotic pairing in B chromosomes of Crepis capillaris. I. One-B and two-B pollen mother cells. Genome, 32, 611-621.
LÓPEZ-LEÓN, M. D., CABRERO, J., PARDO, M. C., VISERAS, E., CAMACHO, J. P. M. AND SANTOS, J. L. 1993. Generating high variability of $\mathrm{B}$ chromosomes in the grasshopper Eyprepocnemis plorans. Heredity, 71, 352-362.

LÓPEZ-LÉON, M. D., NEVES, N., SCHWARZACHER, T., HESLOPHARRISON, J. S., HEWITT, G. M. AND CAMACHO, J. P. M. 1994. Possible origin of a B chromosome deduced from its DNA composition using double FISH technique. Chromosome Res., 2, 87-92.

MAISTRO, E. L., FORESTI, F. AND OlIVEIRA, C. 1994. New occurrence of a macro B-chromosome in Astyanax scabripinnis paranae (Pisces, Characidae). Brazil. J. Genet., 17, 153-156.

MALUSZYNSKA, J. AND SCHWEIZER, D. 1989. Ribosomal RNA genes in B-chromosomes of Crepis capillaris detected by non-radioactive in situ hybridization. Heredity, 62, 59-66.

McAllister, B. F. 1995. Isolation and characterization of a retroelement from a $\mathrm{B}$ chromosome (PSR) in the parasitic wasp Nasonia vitripennis. Insect Mol. Biol., 4, 253-262.

McAlLister, B. F. AND WERREN, J. H. 1997. Hybrid origin of a B chromosome (PSR) in the parasitic wasp Nasonia vitripennis. Chromosoma, 106, 243-253.

SALVADOR, L. B. AND MOREIRA-FILHO, O. 1992. B chromosomes in Astyanax scabripinnis (Pisces, Characidae). Heredity, 69, 50-56.

SANGER, F., NICKLEN, S. AND COUlSON, A. 1977. DNA sequencing with chain termination inhibitors. Proc. Natl. Acad. Sci. U.S.A., 74, 5463-5467.

SANTOS, J. L., JIMÉNEZ, M. M. AND DÍEZ, M. 1995. Synaptic patterns of rye B chromosomes. IV. The B isochromosomes. Heredity, 74, 100-107.

SOUTHERN, E. M. 1975. Detection of specific sequences among DNA fragments separated by gel electrophoresis. J. Mol. Biol., 98, 503-517.

SUMNER, A. T. 1972. A simple technique for demonstrating centromeric heterochromatin. Exp. Cell. Res., 74, 304-306.

VICENTE, V. E., MOREIRA-FILHO, O. AND CAMACHO, J. P. M. 1996. Sex-ratio distortion associated with the presence of a $\mathrm{B}$ chromosome in Astyanax scabripinnis (Teleostei, Characidae). Cytogenet. Cell Genet., 74, 70-75.

XIONG, Y., BURKE, W. D., JAKUBCZAK, J. AND EICKBUSH, T. H. 1988. Ribosomal DNA insertion elements R1Bm and R2Bm can transpose in a sequence specific manner to locations outside the 28S genes. Nucl. Acids Res., 16, 10561-10573. 